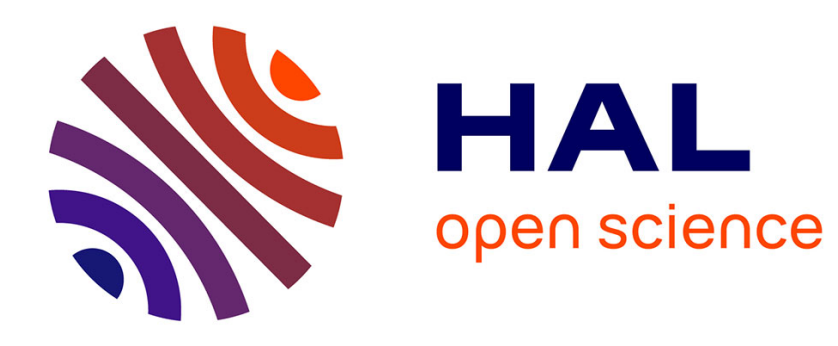

\title{
A GHz SINGLE MODE TUNABLE CO2 RADIOFREQUENCY LASER
}

\author{
S. Marchetti, R. Simili
}

\section{To cite this version:}

S. Marchetti, R. Simili. A GHz SINGLE MODE TUNABLE CO2 RADIOFREQUENCY LASER. Journal de Physique IV Proceedings, 1991, 01 (C7), pp.C7-711-C7-714. 10.1051/jp4:19917193 . jpa00250873

\section{HAL Id: jpa-00250873 https://hal.science/jpa-00250873}

Submitted on 1 Jan 1991

HAL is a multi-disciplinary open access archive for the deposit and dissemination of scientific research documents, whether they are published or not. The documents may come from teaching and research institutions in France or abroad, or from public or private research centers.
L'archive ouverte pluridisciplinaire HAL, est destinée au dépôt et à la diffusion de documents scientifiques de niveau recherche, publiés ou non, émanant des établissements d'enseignement et de recherche français ou étrangers, des laboratoires publics ou privés. 


\title{
A GHz SINGLE MODE TUNABLE $\mathrm{CO}_{2}$ RADIOFREQUENCY LASER
}

\author{
S. MARCHETTI and R. SIMILI \\ IFAM CNR, Via del Giardino 7, I-56100 Pisa, Italy
}

\begin{abstract}
CO}_{2}$ WG laser is briefly described. The laser operatesat high pressure $\mathrm{He}$ free mixtures $(0.4 \mathrm{bar})$, driven by $1 \mathrm{KHz} 1 \mathrm{~kW}$ radiofrequency pulses. A full FSR tuning is obtained over 40 lines at $150 \mathrm{~W}$ peak power and $0.3 \mathrm{~W}$ mean power.
\end{abstract}

\section{Introduction}

High power single mode $\mathrm{GHz}$ tunable $\mathrm{CO}_{2}$ lasers are very interesting in many experiments as LIDAR, optical pumping, high resolution spectroscopy. To achieve this result the free spectral range (FSR)must be increased (the cavity length reduced) ,and the operating pressure must be increased so that the excitation power density is increased squarely to obtain the same laser gain. By using moderate voltages the energy deposition can be increased by using WG discharges. A similar $\mathrm{CW} \mathrm{GHz}$ mode tuned laser is reported in (1) but the WG section is too small to allow grating tuning to other lines than the strongest 10P20 one, and the power is small.On the contrary the WG pulsed TEA lasers can have large power (100W) and $\mathrm{KHz}$ repetion frequency but they have the same tuning problems(2). By using a mini-TEA laser an effective $0.7 \mathrm{GHz}$ tuning with $0.5 \mathrm{MW}$ and few $\mathrm{Hz}$ is obtained over some lines(3) but these devices have not great power and frequency stabilty. On the contrary the TE Radiofrequency excitation allows to operate in $\mathrm{CW}$ at high pressures in large section WG, and a tuning over many $\mathrm{CW}$ lines has been observed(4), but the power is small. In fact at high energy density there is a limit in the laser cooling and the gas must be flowed very fast. Besides at high pressure a RF discharge becomes ionic after few $\mu \mathrm{s}$, so that only a small part of a CW RF energy can be converted in the CW laser emission. To avoid these effects smaller pressures in He reach mixtures are used (4). On the contrary by pulsing a high power RF discharge both the peak power than the mean power can be increased at larger pressures (5). The only problem is the frequency chirp (due to gas heating in the pulse time,) which acts as a mean linewidth enlargement. At $1 \mathrm{bar}$ and $1 \mathrm{~kW}$ this enlargement is expected lower than $30 \mathrm{MHz}$ in standard mixtures ,and $20 \mu \mathrm{s}$ time pulse(6), so this approach is very interesting.

\section{Experiment}

Our RF laser design has been reported previously ( 7 ) and described in fig 1.

The WG tube is dressed with two copper tubes (E) with internal water circulation (W) allowing both the transverse discharge and the laser cooling. A $29 \mathrm{MHz}$ RF pulse generator (power $=0-1$ $\mathrm{KW}$, pulse duration $=3 \mu \mathrm{s}$-continuous) is matched to the laser by means of the matching box MB. To obtain a larger repetition frequency, the gas $(\mathrm{g})$ is inserted at the WG ends and ejected(pumped) at the WG centre, also to avoid : : the windows/mirror thermal damage. The 

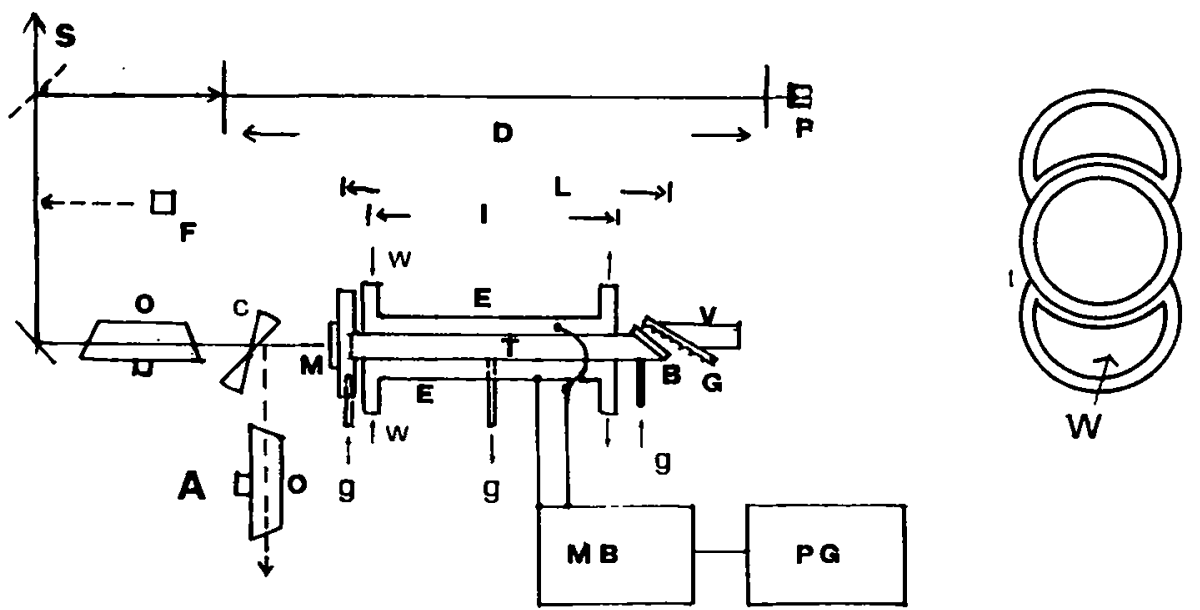

$\mathbf{B}$

Fig1. A)experimental set-up ( see text).B)WG section (W=water)

circular WG radius $=1.4 \mathrm{~mm}$ allows a beam dimension enough large to ensure grating line separation also for the weaker lines. The discharge length is $I=103 \mathrm{~mm}$ while the cavity length $(L)$ is $16 \mathrm{~cm}$ about corresponding to $L(2 \mathrm{c})=940 \mathrm{MHz} F S R$. ( $c$ the light velocity). The mode tuning is achieved by means of a PZT (V) grating (G) translation .

The coupling mirror $M$ has $7 \%$ transmission and the total cavity loss per trip is about $15 \%$.

The emitted power can be sent to two optoacustic cells $(O)$, to a monochromator $(S)$, 10 a fast detector (F) and finally it is sent through a refence cavity (with $D$ distance), to a pyroelectric $P$ ,so that ,by means of the transmission interferences, we can measure the mode tuning vs. the PZT voltage and the mean laser linewidth from the fringes visibility vs. the cavity distance $D$. At 10 liter. atm /min gas flow a $\mathrm{KHz}$ repetition frequency is obtained at the maximum peak power. This is a large flow and to reduce the laser running expences the $\mathrm{He}$-free mixture $\mathrm{CO}_{2}: \mathrm{N}_{2}=1: 2$ is used at about $0.4 \mathrm{~atm}$. With 0.4 atm $1: 2$ mixture the laser gain $g(v)$ is enlarged by collisions as $g(v)=1 /\left(1+\left(v-v_{0}\right)^{2} / \Delta_{p}{ }^{2}\right)$



Fig2. 10P20 pulsed emission. time scale $5 \mu \mathrm{s}$, power scale $30 W . O$ is RF pulse onset, $E$ the RF end of pulse 


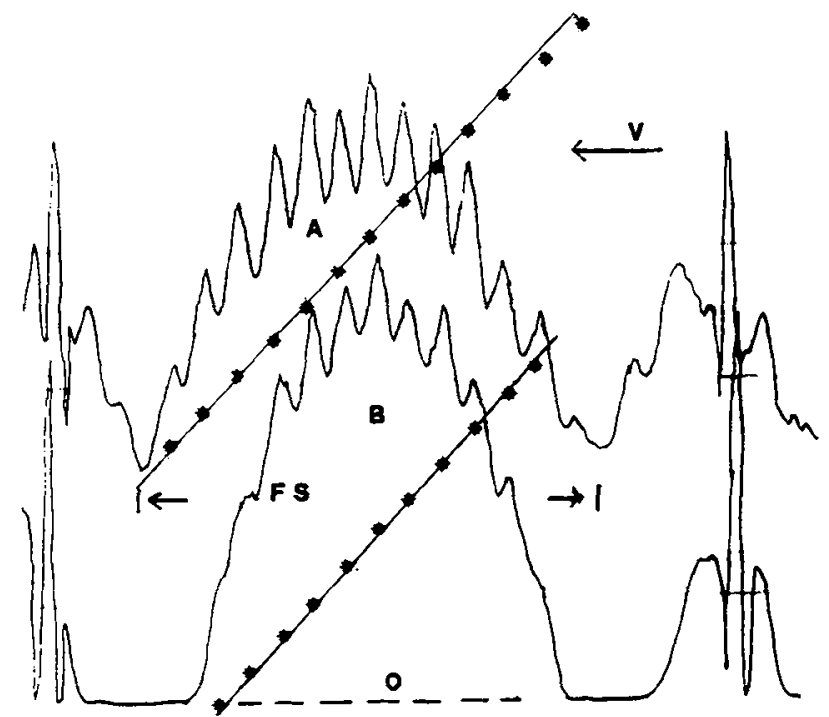

Fig3. The mode tuning through the reference cavity (see text)

with $\Delta_{p}=1 \mathrm{GHz}$ so that the FSR pulling reduction is expected lower than $40 \mathrm{MHz}$ (7).

\section{Results}

A standard laser pulse is reported in fig 2 .The laser pulse has a 7-10 $\mu$ s build-up time and the laser gain turn off $20 \mu \mathrm{s}$ after the RF onset due to the fast ionic degeneration so that the RF pulse is ended a this time. More than $150 \mathrm{~W}$ peak pulse is obtained with $300 \mu \mathrm{J}$ energy pulse. The effective mode tuning vs. the PZT voltage (v) is reported in fig 3 for the 9P22 (a) and 9P28 (b) lines. The fringe spacing was $67 \mathrm{MHz}$ and the effective FSR about $.92 \mathrm{GHz}$. The PZT non linearity is well shown, while the pulling is lower than expected.

The fringes are not detectable with $D>4 \mathrm{~m}$ (fig.4) so that according with the Raylegh criterion, the laser linewidth is smaller than $c /(24 \mathrm{~m})=40 \mathrm{MHz}$.



Fig 4. The visibility $\left(I_{\max }-I_{\min }\right) / I_{\max }$ vs. the $D$ distance 


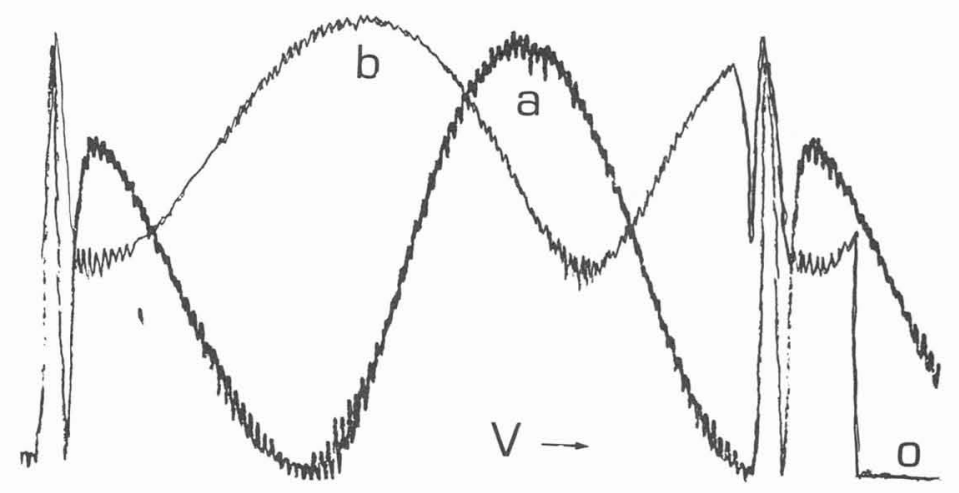

Fig 5. The $10 \mathrm{R} 28$ scan in $\mathrm{He}$ free (a) and He reach mixture (b). (see text).V=PZT voltage, $\mathrm{O}=z e r 0$ power

When a 1:1:3 He reach mixture is used at 1 bar both the full tunable line number and the mean power are increased. Fig 5 shows this effect on the 10R26 line.

\section{Conclusion}

A RF $\mathrm{CO}_{2}$ laser, nearly $\mathrm{GHz}$ mode tunable over many lines is reported. High peak power and good mean power are obtained in unexpensive $\mathrm{He}$ free mixtures at $0.4 \mathrm{~atm}$. The frequency chirp enlarges the laser mean linewidth but it is always subdoppler $(<40 \mathrm{MHz})$

\section{References}

1)R. Abrams: Appl.Phys.Lett 25, 304,(1974)

2)P.W. Smith et al. :IEEE J.Quant. Electron QE17, 1166, (1981)

3) H.N. Rutt ,D.N. Travis, K.C. Hawkins: Int. J. Infrared \& MMW 5, 1201 (1984)

4)S. T. Kornilov et al . a) Opt. Comm 66, $149,(1988)$ b) Int. J. Infrared \& MMW 10, 419, (1989)

5)J. Lachambre ,J. Macfarlane,G .Otis, P.Lavigne:Appl.Phys. Lett.32 , 652(1978)

6) S. Lovold,: IEEE J. Quant, Electron QE24,2514 (1988)

7) S Marchetti, R. Simili: a) N. Clmento lett $42,32,(1985)$ b) N . Cimento D 10D, 1005 (1988) 